\title{
СОВРЕМЕННОЕ СОСТОЯНИЕ ИНВЕСТИЦИОННОЙ ПРИВЛЕКАТЕЛЬНОСТИ ЭКОНОМИКИ АЗЕРБАЙДЖАНА
}

\author{
(c) 2020 Джаббарова Гюнель Интизам кызы \\ докторант \\ Азербайджанский Университет Кооперации, Азербайджанская Республика, Баку \\ E-mail: gunel.cabbarova@azeravtoyol.gov.az
}

В статье исследуется современное состояние инвестиционной привлекательности Азербайджана, оценивается созданная в этой сфере среда. Выдвигаются факторы, влияющие на повышение инвестиционного потенциала страны, и оценивается инвестиционная привлекательность национальной экономики.

Ключевые слова: инвестиции, инвестиционный потенциал и привлекательность, ненефтяной секmop.

\section{Введение}

Расширение экономики и развитие ее отраслей в Азербайджанской Республике увеличивает спрос на инвестиционные вложения. Удовлетворение такого спроса, привлечение иностранных инвестиций в сферы экономики страны, в частности в аграрный сектор напрямую зависит от инвестиционной политики, проводимой государством. Следует уделить особое внимание инвестиционной привлекательности и увеличению инвестиций в экономику страны. Такой взгляд находит свое отражение и в государственных программах и концептуальных документах, принятых в стране в последние десять лет.

\section{Возможности инвестиционной привле- кательности Азербайджана}

Инвестиции играют важную роль в увеличении реального общего капитала, стимулировании экономической эффективности, формировании конкурентоспособной национальной экономики. Рост инвестиционной привлекательности страны выступает и как один из основных инструментов стабилизации и перспективного развития экономики [1]. Одним из важнейших направлений развития рыночной экономики в Азербайджане является развитие предпринимательства в регионах страны. С этой целью в принятых в стране региональных программах особое внимание уделяется развитию частного сектора и повышению его инвестиционной привлекательности. В частности, развитие инвестиционной среды в Азербайджане больше связано с развитием не-нефтяного сектора [2; 3].

Имеются широкие возможности в сфере раз- вития не-нефтяного сектора Азербайджана. Так, на плодородных землях страны выращиваются необходимые сельскохозяйственные продукты (хлопок, виноград, зерно, табак, чай, фрукты и овощи и т.д.). Благодаря увеличению инвестиций в эту сферу будет действовать развитие аграрного и перерабатывающего сектора страны. А также, природно-климатические условия Азербайджана и наличие досуга открывают новые возможности для увеличения притока иностранных инвестиций в экономику. В последнее десятилетие экономика страны проявляет интерес к иностранным инвестициям, и это связано в основном со следующими факторами:

- Наличие богатых природных ресурсов, сырьевых ресурсов Азербайджана;

- Наличие необходимой дешевой рабочей силы в стране;

- Наличие квалифицированного научнотехнического кадрового потенциала;

- Географическое положение Азербайджана и транспортные связи;

- Наличие благоприятных условий для выхода отечественной продукции на мировой рынок.

Азербайджан имеет достаточную сырьевую базу для развития различных отраслей обрабатывающей промышленности. Многие предприятия и производства, основанные на этих сырьевых ресурсах и их переработке, считаются прибыльными и быстро окупаемыми [4]. В Азербайджане приняты нормативно-правовые документы, необходимые для защиты прав иностранных инвестиций. Также необходимо применение льготных налоговых механизмов для 
обеспечения устойчивого развития экономики страны, привлечения внутренних и иностранных инвестиций во все сферы.

Оценка инвестиционной привлекательности экономики Азербайджана

Рост валового внутреннего продукта (ВВП) в Азербайджане обусловлен увеличением объема инвестиций в экономику. По сравнению с 2014 годом объем инвестиций в экономику в 2018 году увеличился на 20\%. Если в 2014 году доля инвестиций в экономику составляла 37\% в ВВП, то в 2018 году этот показатель снизился на 4\% и составил 33\%. Государственные инвестиции отличаются более высокой долей инвестиций в экономику (40\%) [5; 6]. Эти инвестиции в основном направлены на различные сектора, в основном в области инфраструктуры, по линии государственных программ, принятых в стране.

В стране за последние пять лет проявилась тенденция к различным изменениям в объеме инвестиций в основной капитал по сферам экономики. Рост инвестиций в основной капитал наблюдался в промышленном и строительном секторах. Так, по сравнению с 2014 годом объем инвестиций в основной капитал в 2018 году увеличился в 2,3 раза, в строительном секторе-в 24,8 раза. Напротив, в сельском хозяйстве соответствующий показатель снизился в 1,3 раза, в транспортном секторе в 1,8 раза, в сфере информации и связи на $6 \%[5 ; 6]$.

В Азербайджане большая часть инвестиций в основной капитал в промышленности приходится на нефтегазовый сектор. Если в 2010 году доля промышленности в структуре инвестиций в основной капитал по отраслям экономики составила 43\%, то в 2018 году этот показатель вырос на 20\% и достиг 63\%. В других областях, в том числе в областях, входящих в не-нефтяной сектор (обрабатывающая промышленность, сельское хозяйство, транспорт, информация и связь и т.д.) более заметны тенденции снижения объема инвестиций в основной капитал. Кроме того, более $60 \%$ инвестиций в основной капитал в Азербайджане приходится на долю столицу. В организации и развитии своей деятельности инвесторы отдают предпочтение именно столице и ее окрестным регионам.

По сравнению с 2010 годом в 2018 году объем инвестиций в основной капитал в промышленном секторе вырос в 2 раза и достиг 8,5 млрд. azn. В сопоставимом периоде объем иностранных инвестиций в промышленность увеличился в 2,1 раза, а внутренние инвестиции в 2 раза [6; 7]. В последнее годы объем внутренних инвестиций, направленных в промышленность страны, также заметно растет благодаря своей высокой доле.

В Азербайджане особое внимание уделяется повышению инвестиционной привлекательности ненефтяного сектора. Такие инвестиции имеют особое значение с точки зрения модернизации и совершенствования основных фондов этого сектора. Экономическая политика, проводимая в последнее десятилетие, оказывает свое влияние на развитие горнодобывающей и перерабатывающей промышленности [1; 2]. Так как, диверсификация этих областей постепенно углубляется, в основном за счет ввода в эксплуатацию новых производственных мощностей, создается благоприятная основа для улучшения

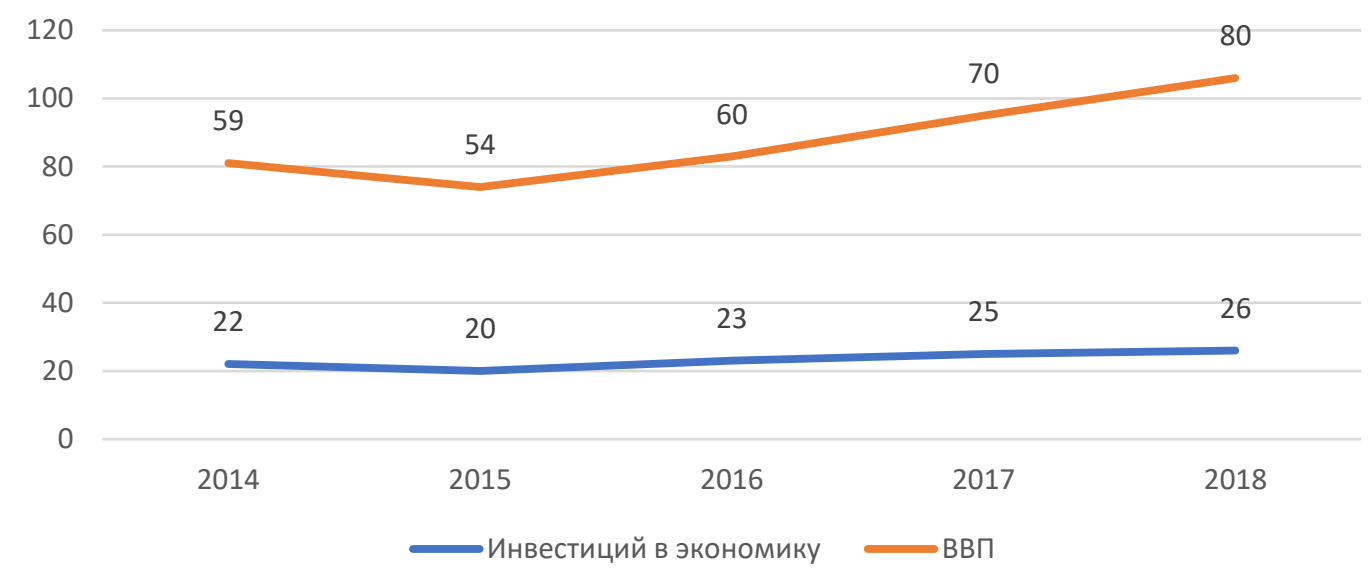

Динамика роста ВВП и инвестиций в экономику (млрд. azn). Источник: www.economy.gov.az; https: www.stat.gov.az. 


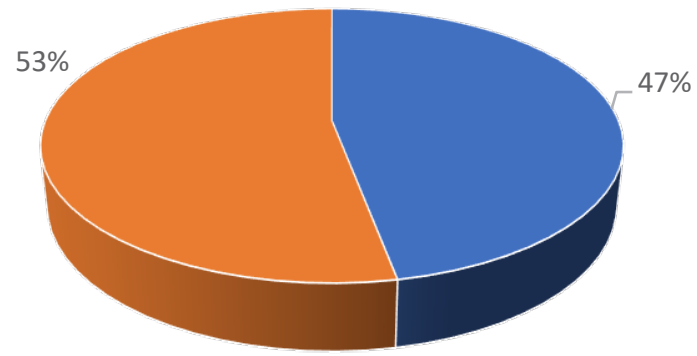

- иностранные инвестиции внутренние инвестиции

Распределение доли инвестиций в промышленном секторе (2018,\%)

Источник: www.economy.gov.az; https: www.stat.gov.az.

основных фондов действующих предприятий.

В инвестициях в промышленность наблюдаются достаточные различия по сферам. В частности, объем инвестиций в горнодобывающую промышленность (основной нефтегазовый сектор) заметно возрос. Так, если в 2010 году объем инвестиций в нефтегазовый сектор составил 54\% от общего объема инвестиций в промышленность, то в 2018 году этот показатель вырос на $13 \%$ и достиг $67 \%$. Соответствующие инвестиции состоят как из государственных, так и иностранных инвестиций. В 2010 году доля инвестиций в обрабатывающую промышленность в общем объеме инвестиций в промышленный сектор составила 12\%, в 2018 году этот показатель вырос до определенного уровня - 17\% [6; 7]. Следует отметить, что инвестиции в эту сферу осуществлялись в основном за счет внутренних ресурсов частного сектора.
В обрабатывающей промышленности Азербайджана имеются широкие возможности для создания новых производственных мощностей. Считаем целесообразным, наряду с расширением объемов производства в этой сфере, продолжить меры по созданию новых перерабатывающих предприятий. Также особое внимание следует уделить фактору использования энергосберегающих технологий, отвечающих высоким экологическим требованиям при создании новых промышленных предприятий и эксплуатации основных производственных фондов. Хотя в последнее время в развитии перерабатывающей промышленности, являющейся основной ведущей отраслью не-нефтяного сектора в стране, происходят успехи, но капиталовложений в эту сферу пока не наблюдается с высоким уровнем. По сравнению с 2010 годом объем инвестиций в обрабатывающую промышленность в 2018

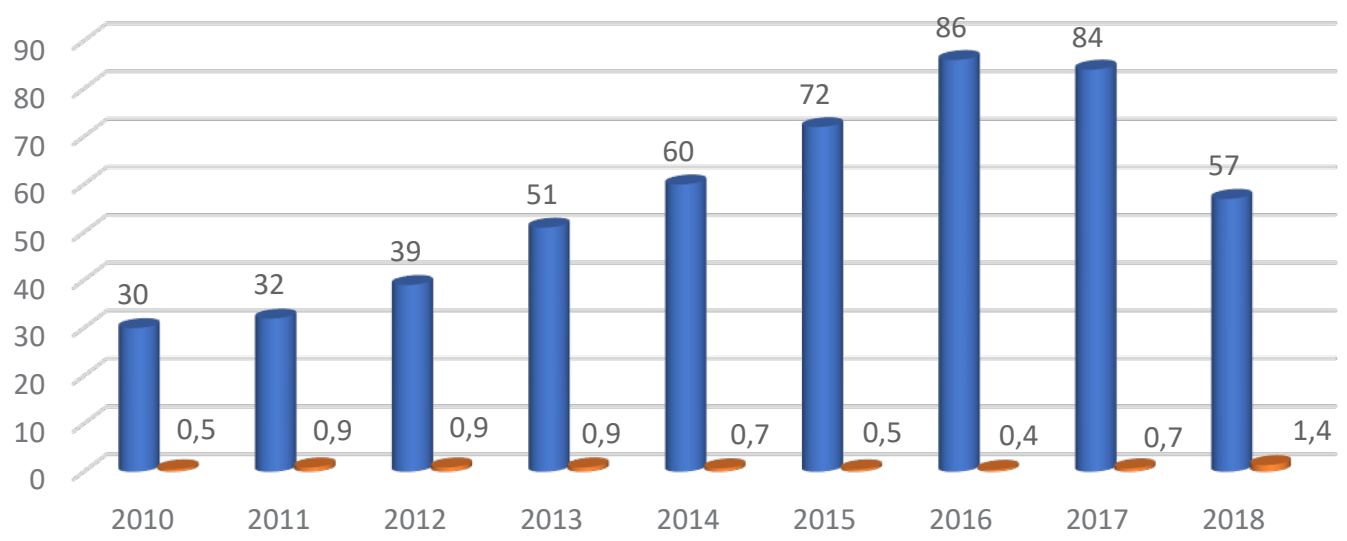

п Горнодобывающая промышленность — Обрабатывающая промышленность

Инвестиции в основной капитал в промышленности (млрд. azn) Источник: https: www.stat.gov.az; www.cbar.az/assets/3577/Bulleten-2017_mart.pdf. 
году вырос в 2,8 раза и достиг 1,4 миллиарда azn [6; 7]. Несмотря на проведение необходимых мер и реформ по дальнейшему улучшению ситуации в существующей сфере, потребности в развитии обрабатывающей промышленности высоки.

Продукция, производимая на предприятиях не-нефтяной промышленности страны, имеет высокую трудоемкость и материалоемкость. В этой области низкий объем инновационных и наукоемких продуктов. В то же время, отсутствие конкурентоспособности продукции большинства предприятий не-нефтяной промышленности (в том числе химической) связано с низким уровнем существующих производственных мощностей, физическим и моральным износом используемого оборудования и технологий. Объем научно-исследовательских расходов в не-нефтяной промышленности резко отличается низким уровнем. Исследования еще раз показывают, что в стране должна быть решена проблема модернизации и совершенствования основных промышленно-производственных фондов. В частности, высокий спрос на обновление производственных фондов, существующих в не-нефтяной промышленности. Естественно, решение этой важной проблемы в первую очередь привлекает на первый план фактор целевых и крупных инвестиций.

Развитие малого предпринимательства в экономике Азербайджана считается одной из основных приоритетных сфер. В этом направлении также были приняты необходимые государственные программы и правовые документы. Действующих в стране 78\% предприятий счита- ются малыми предприятиями. Кроме того, 31\% таких предприятий действует в сфере торговли, $13 \%$ в сфере услуг, $12 \%$ в строительстве, $11 \%$ в сфере сельского хозяйства и 33\%-в других сфеpax $[5 ; 6]$.

По сравнению с 2010 годом в 2018 году инвестиции субъектов малого предпринимательства в основной капитал вырос в 3,7 раза и достиг 1,1 миллиарда azn. Инвестиционные вложения, играющие важную роль с точки зрения развития малого предпринимательства в стране, осуществляются преимущественно за счет внутренних источников. С другой стороны, недостаточно высокий уровень инвестиций субъектов малого предпринимательства создает проблемы их развития. За последние десять лет доля инвестиций в основной капитал субъектов малого предпринимательства в общем объеме инвестиций не превышает 5\%. По всем сферам экономики баланс инвестиций в основной капитал субъектов малого предпринимательства также не наблюдается. Так как, 32,5\% соответствующих инвестиций приходится на промышленность, 9,2\% на сельское хозяйство, $14,6 \%$ на строительство, $32,5 \%$ на торговлю и общественное питание [6; 7].

За последнее десятилетие объем кредитных вложений в экономику со стороны банков заметно вырос. Так, по сравнению с 2010 годом объем кредитных вложений банков в экономику в 2018 году вырос в 1,4 раза и достиг 13 миллиардов azn. В течение сравнительного периода доля долгосрочных кредитов в кредитных вложениях также наблюдалась с достаточно высокой.

В повышении уровня долгосрочных кредит-

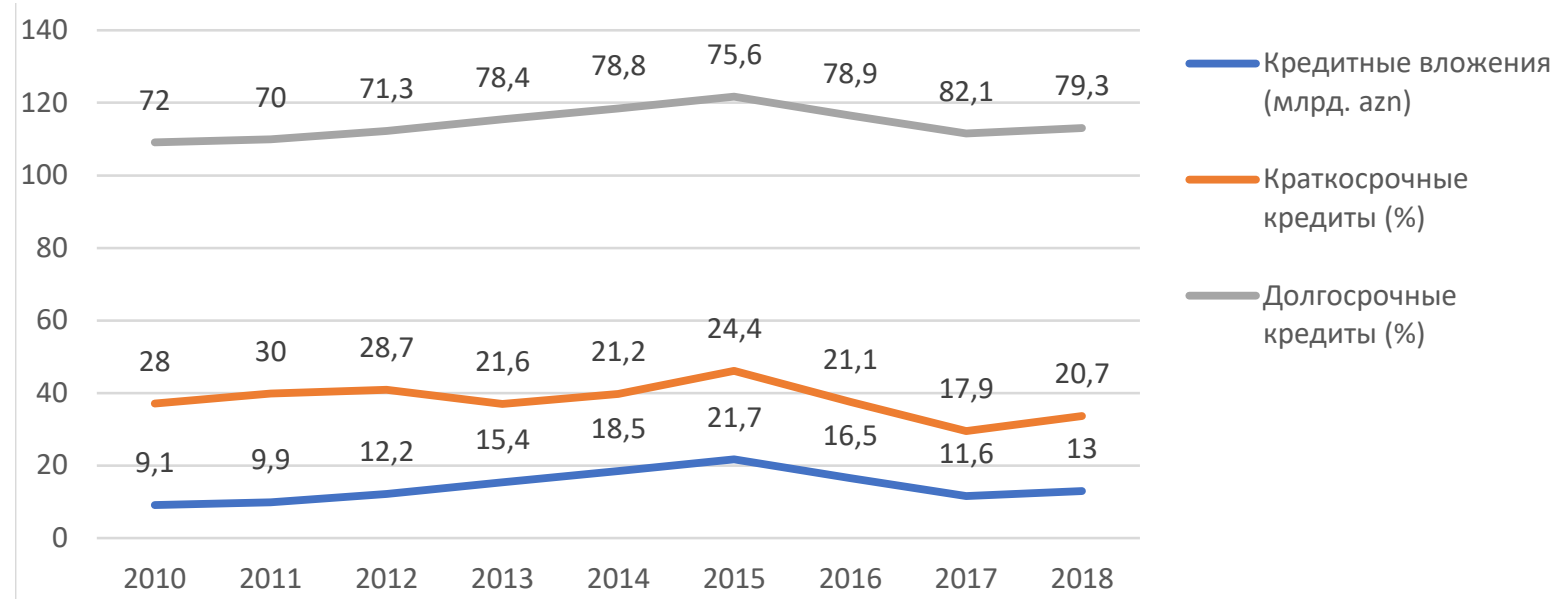

Кредитные вложения банков в экономику

Источник: https: www.stat.gov.az; www.cbar.az/assets/3577/Bulleten-2017_mart.pdf. 
ных вложений экономики важную роль играют государственные программы, реализуемые в стране. В частности, на рост таких кредитов оказывает положительное влияние объем инвестиций в инфраструктурные проекты за счет бюджетных средств.

Опыт страны показывает, что, хотя и происходят позитивные улучшения в области кредитных вложений, выделяемых по всем источникам, но рост процентных ставок по кредитам, предоставляемым банками и кредитными организациями, не создает широкие возможности для использования этих финансовых ресурсов не-нефтяной промышленностью. Серьезные проблемы последнего периода в деятельности банковских организаций приводят к сужению политики их кредитных вложений.

\section{Выводы}

Для улучшения инвестиционной привлекательности экономики Азербайджана такие меры необходимы:

- Внедрение льготных механизмов для предприятий с перспективным и потенциальным развитием;

- Предоставление льготных кредитов не-нефтяному сектору для улучшения его технической базы;

- Улучшение инвестиционного обеспечения для повышения экспортного потенциала предприятий не-нефтяного сектора;

- Повышение инвестиционной привлекательности инновационной деятельности;

- Предоставление стимулирующих предприятий для повышения тенденций производства конкурентоспособной продукции, ориентированной на инновации.

\section{Библиографический список}

1. «Азербайджан 2020: взгляд в будущее» Концепция Развития. Баку, 2012.

2. «Государственная программа о развитии промышленности в Азербайджанской Республике на 2015-2020 годы». Баку, 2015.

3. «Стратегическую дорожную карту по перспективе национальной экономики Азербайджанской Республики». Баку, 2016.

4. Стратегическую дорожную карту относительно производства потребительских товаров на уровне малого и среднего предпринимательства в Азербайджанской Республике». Баку, 2016.

5. www.economy.gov.az;

6. https: www.stat.gov.az;

7. www.cbar.az/assets/3577/Bulleten-2017_mart.pdf 